\title{
The role of technological capabilities in the competitive advantage of companies in the Campinas, SP Tech Hub
}

\author{
Valdir Antonio Vitorino Filho and Roberto Giro Moori \\ Universidade Presbiteriana Mackenzie, Sao Paulo, Brazil
}

Role of technological capabilities

Received 24 August 2017 Accepted 22 November 2017

\begin{abstract}
Purpose - This study aims to examine the role of technological capabilities in the competitive advantage of supply chains for the "countryside" hub of São Paulo state.

Design/methodology/approach - An interdisciplinary approach was adopted by combining the strategic orientation of supply chain management as a link between market and operational activities, with technological capabilities as an essential factor for competitive advantage. This exploratory, mixed-method study was conducted in the Campinas technology hub, which has become important for its available skilled workforce, and broad and structured supply chain. The study sample included ten companies and dealt with the techniques of content analysis and non-parametric statistics - the Mann-Whitney U technique.

Findings - The results revealed that strategic supply chain management has an impact on technological capabilities and competitive advantage.

Originality/value - They also showed that technological capabilities have a partial mediating effect on competitive advantage.
\end{abstract}

Keywords Supply chain management

Paper type Research paper

Theme 01 - sector studies about innovation and technology

\section{Introduction}

The main theme of this research study is related to strategic supply chain management (SSCM), technological innovation capabilities (TICs) and competitive advantage (CA).

The location of this research was the technology hub of Campinas, São Paulo state, the largest in Latin America, known as "Brazil's Silicon Valley". This region accounts for 15 per cent of the country's technology output. The municipality is home to 32 of the world's 500 largest information technology companies (Aquim, 2015).

The Campinas Technology Hub proposes the integration of innovation laboratories for research and development $(\mathrm{R} \& D)$ projects in a single physical space, and features partnerships between public and private companies and institutions, as well as incubators

(C) Valdir Antonio Vitorino Filho and Roberto Giro Moori. Published in Innovation \& Management Review. Published by Emerald Publishing Limited. This article is published under the Creative Commons Attribution (CC BY 4.0) licence. Anyone may reproduce, distribute, translate and create derivative works of this article (for both commercial and non-commercial purposes), subject to full attribution to the original publication and authors. The full terms of this licence may be seen at http:// creativecommons.org/licences/by/4.0/legalcode

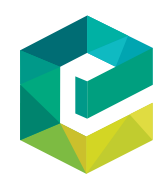

Innovation \& Management Review Vol. 15 No. 3, 2018 pp. $247-268$ 
INMR

15,3

for technology companies, environments conducive to innovation projects and innovation pre-incubators (Inova, 2016).

This study examines supply chain management (SCM) operating at three levels: strategic, tactical and operational (Cooper et al., 1997). The highest level of SCM decisions is the strategic (SSCM), which is relevant to the entire organization (Poirier and Reiter, 1996). Decisions should reflect the company's overall strategy (Christopher, 2000). The processes in SSCM include the development of new products and services, suppliers, manufacturing, customers and all logistics (Simchi-Levi et al., 2008).

The analysis of TICs has been considered important, and can be understood as a comprehensive set of an organization's characteristics, which facilitate and support its technological innovation strategies (Bell and Pavitt, 1993; Lall, 1992). TICs can be understood as the skills and knowledge needed to use or operate existing technologies or production systems, or the ability to change or innovate technologies and production systems (Lau et al., 2010; Yam et al., 2004).

According to Burgelman et al. (2004), technological capabilities are fundamental for companies to acquire competitive advantage. However, for Hall (2004), competitive advantage exists not only because of technological capabilities, but also owing to the application and integration of existing technologies. Paulraj and Chen (2007) posit that technologies and technological capabilities require careful analysis because they can present both advantages (such as improving product quality and reducing costs) and disadvantages (such as cost of investment for operation and need for large volume production). TICs are related to SSCM and CA, through changes or enhancements of products and processes, and connect additional and distinct resources that allow the independent management of technological changes (Yam et al., 2004).

Thus, as an object of academic and scientific study, we identified an epistemological knowledge gap about the role of technological capabilities in the relationship between SCMs' strategic orientation and competitive advantage, which led to the basic question of this research: What is the role of technological capabilities in the relationship between the strategic orientation of SCM and the competitive advantage of the Campinas Technological Hub? The objective was to examine the mediating role of technological capabilities in the competitive advantage of the supply chains of the companies that compose this technological hub.

\section{Theoretical framework}

According to Porter (1980) and Burgelman et al. (2004), technological capabilities are essential for competitive advantage. However, authors such as Hall (2004) consider that competitive advantage exists not only because of technological capabilities, but also because of the application and integration of existing technologies. Ritzman and Krajewski (2004) argue that technologies and technological capabilities require careful analysis because they may present advantages (product quality improvement and cost reduction) but also disadvantages (operation investment cost and large volumes requirements).

In the context of the SSCM orientation, technologies and technological capabilities can act as a mediating factor: that is, their presence causes SSCM to gain competitive advantage.

Figure 1 shows the performance dynamics of technologies and technological capabilities (TICs) in the relationship between SSCM and CA.

To operationalize the empirical mediation model, according to Baron and Kenny (1986) and Lakatos and Marconi (1991), the mediator variable (TIC) is that which, in a sequence, is placed between the independent variable (SSCM) and the dependent variable (CA). Its function is to amplify, reduce or cancel the influence of SSCM on CA, and it is, therefore, 
considered a consequence of the independent variable (SSCM) and determinant of the dependent variable (CA).

Therefore, to assert that a variable (TIC) is a mediator, it is necessary to have three asymmetric relations:

(1) the direct original relation between the independent variable (SSCM) and the dependent variable (CA), represented in Figure 1(a) by the path c;

(2) relationship between the independent variable (SSCM) and the mediator variable (TIC), with the mediator variable (TIC) acting dependent on the independent variable (SSCM), represented in Figure 1(b) through path a; and

(3) relationship between the independent variable (SSCM), represented in Figure 1(b) by the path c', and the mediator variable (TIC), represented in Figure 1(b) by path b. Both relations, SSCM and TIC, act as independent variables of the dependent variable $(\mathrm{CA})$.

In mediation, when paths "a" and "b" are controlled, fading or attenuation of the magnitude of path c (original) in relation to path c' occurs. Obviously, TIC could be treated as a variable antecedent to SSCM, or even a variable consequent to $\mathrm{CA}$. These abstractions are made from an endless chain, and the greater the understanding of the links in that chain, the better the understanding of that relationship. In the specific case of this study, the object will be focused on the mediation of TIC in the relationship between SSCM and CA.

The details of the literature review and assumptions, which support the empirical model shown in Figure 1, are described next. Vergara (2013) suggests the use of the term "assumption" instead of "hypothesis" in qualitative studies, to avoid implying testing, but rather confirmation (or not) via non-statistical mechanisms.

DIRECT EFFECT - represented in Figure 1(a) through path c.

\subsection{Strategic supply chain management and competitive advantage - Path c}

Gunasekaran et al. (2004) argue that SCM has been an important component of competitive strategy, which contributes to increased productivity and organizational profitability. The literature addressing SCM strategies and technologies is vast, and in recent years the measurement of performance and adoption of metrics have received much attention from researchers and practitioners.

Performance measurements for the supply chain (SC) have assumed two perspectives. The first concerns its impact on operational performance, based on the four traditional competitive priorities - cost, quality, flexibility and delivery performance (Ferdows and De Meyer, 1990).

In the second, financial performance is measured by financial and market indicators, such as market growth, return on investment, sales growth and sales profit margin (Kaplan and Norton, 1992; Li et al., 2006).

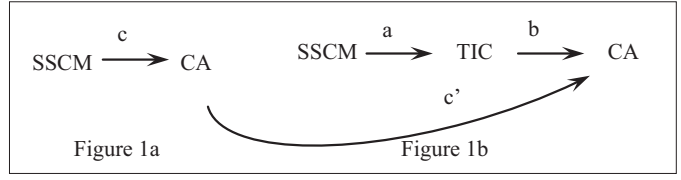

Source: Authors

Figure 1. The empirical mediation model 
INMR

15,3

Technological competence can be defined as a set of resources necessary for the development of technological transformations, such as knowledge, skills and experiences (Bell and Pavitt, 1995).

Some studies analyze the relationship between SSCM and CA: for example, the skills pertaining to supply chain integration and their impact on SCM performance, in a study with SCM professionals in the USA (Eltantawy et al., 2009); supplier development practices and their effects on supplier-customer relationship performance in electronics companies in Hong Kong (Li et al., 2012); and the relationship between the formation of partnerships for best practices in environmental SC and performance results, in a study with Korean companies (Youn et al., 2013). These studies pointed to the positive influence of SSCM on the CA of the companies surveyed, demonstrating that the more strategically structured their supply chain, the better their performance indicators and their CA in relation to their competitors.

On the basis of the above, the following four assumptions are made:

Assumption 1: Strategic supply chain management positively influences competitive advantage.

INDIRECT EFFECT: represented in Figure 1(b) by paths a and b.

\subsection{Strategic supply chain management and technological innovation capabilities - Path a}

SSCM should seek the alignment of key organizations to achieve an effective flow of tangible and intangible goods to meet customers' wants and needs, bringing returns to the entire chain (Paulraj and Chen, 2007; Sukati et al., 2012).

SC's strategic management can be said to involve decisions that shape long-term corporate capacity-chain capabilities and their overall strategy, through reconciliation and ongoing adjustments to market and resource requirements (Melnyk et al., 2006).

It should be noted that there is a difference between production capabilities and technological innovation capabilities (Bell and Pavitt, 1993; Lall, 1992). Production capabilities are related to the routine operations of companies, involving the resources for the production of goods and services and making use of factors such as skills, equipment, organizational systems and management methods (Chiesa et al., 1996; Christensen, 1995). Technological innovation capabilities concern the modification or improvement of products and processes, and incorporate additional and distinct resources that allow the management of technological changes independently (Burg et al., 2004).

The relationship between SSCM and TIC has been intensively studied in recent years, and studies have addressed: the impact of socialization and TIC mechanisms on the integration of the SC in Taiwanese manufacturing companies (Lin, 2014); the creation of technological innovation through green SCM in industrial enterprises in Malaysia (Lee et al., 2014); and the importance of the strategic view in SCM for the development of new products with UK producers through improvements in the suppliers' creative and technological capabilities (Lawson et al., 2015). These studies conclude that SSCM increasingly relies on TIC investments to manage complex relationships, large quantities and the exchange of information in the chain, as well as the needs for adaptation and rapid changes in relation to other competing chains.

In this context, this study proposes the following assumption:

Assumption 2: The strategic management of the supply chain positively influences technological innovation capabilities.

\subsection{Technological innovation capabilities and competitive advantage - Path b}

Some measurement scales for TIC were developed using a functional approach, with seven capability dimensions (Guan and Ma, 2003; Lau et al., 2010; Yam et al., 2004), briefly described as follows: 
(1) learning capability, the company's ability to identify and assimilate explicit knowledge in the environment;

(2) R\&D capability, the company's ability to integrate research and development strategy with project implementation;

(3) resource allocation capability, the company's ability to acquire sufficient capital, professionals and technology for the innovation process;

(4) manufacturing capability, the company's ability to transform $\mathrm{R} \& \mathrm{D}$ results into products that meet the needs of the consumer market;

(5) marketing capability, the company's ability to advertise and sell its products;

(6) organizational capability, the company's ability to ensure organizational mechanisms that are in accordance with the organizational culture and the adoption of good management practices; and

(7) strategic planning capability, the company's ability to identify strengths and weaknesses as well as opportunities and threats, and formulate action plans in accordance with corporate vision and mission.

Tang and Liou (2010), Vasconcelos and Cyrino (2000) and Wiggins and Ruefli (2002) argue for the existence of four distinct models of concepts and explanations of competitive advantage, with their premises focused on the following dimensions:

(1) industrial organization, with technical production functions and a set of complementary activities, where the source of competitive advantage is tied to the attractiveness and positioning of the firm within the sector (Ghenawat, 1991; Porter, 1980; Shapiro, 1989);

(2) resources, with an analysis of the stability of resources, skills and capabilities, in which privileged access to unique, hard-to-imitate resources supports the source of competitive advantage (Barney, 1991);

(3) market processes, stimulating entrepreneurial activity, producing innovations and generating knowledge to strengthen the concepts of innovation and creative destruction (D'Aveni and Gunther, 1994; Jacobson, 1992); and

(4) dynamic capabilities - composed of an evolutionary set of resources, competencies and capabilities - to gain competitive advantage through routines and organizational processes that are able to regenerate the firm's resource base (Amit and Schoemaker, 1993; Dierickx and Cool, 1989; Sanchez et al., 1996; Teece et al., 1997).

Other important studies were conducted by $\mathrm{Hu}$ (2012) on the relationship between TIC and CA in the crystal monitor industries in Japan, South Korea and Taiwan, and by Azubuike (2013), about the development of new products in the plastic manufacturing industry in Nigeria. Their results pointed out that investments in technological capabilities for products and processes can lead to a company's superior performance.

Hence, this study investigates a third assumption:

Assumption 3: Technological innovation capabilities positively influence competitive advantage. MEDIATION EFFECTS - represented in Figure 1(b) by path c', under the impact of path b.

\subsection{Mediator effect of technological innovation capabilities - Path c'}

TICs are related to SSCM and CA through changes or enhancements of products and processes, and connect additional and distinct capabilities that allow the independent management of technological change (Yam et al., 2010). 
INMR

15,3

Yam et al. (2010) argue that the measurement of technological innovation can be accomplished in seven dimensions of capabilities: learning, R\&D, resource allocation, manufacturing, marketing, organization and strategic planning. Such capabilities are reflected by technological innovation, sales performance, product performance and sales growth.

Ortega (2010) evaluated the role of TIC in mediating the relationship between competitive strategies and company performance, with a sample of 253 communications technology companies in Spain. The results indicated that TICs improve the relationship between quality and cost performance orientation, suggesting that the theoretical prescriptions of the RBV and competitive strategy should be combined by the companies to greater effect.

Shan and Jolly (2013) conducted a survey of 215 Chinese companies in the electronics industry, and showed that the different TICs have a positive impact on product innovation, starting with linkage capacity, then production capacity and finally investment capacity. The research concludes that TICs have a mediating effect on the relationship between different SSCMs and company performance.

Finally, Noor and Aljababi (2016) indicate that absorptive capacity and entrepreneurial orientation significantly impact TICs in small and medium-sized companies in the construction sector.

On the basis of these findings, the following assumption is made:

Assumption 4: Technological innovation capabilities measure the relationship between strategic supply chain management and competitive advantage.

\section{Methodology}

\subsection{Nature, type of survey and sample size}

This exploratory study used the triangulation or mixed method research design (Creswell, 2007). The reason for the choice of this method was the need to integrate, in a single detailed investigation, different qualitative and quantitative data slices to guarantee a better understanding of the problem studied (Creswell, 2007). Direct observations, secondary data extracted from scholarly specialized journals and primary data were the sources for data collection.

As for the size of the sample, interviews were attempted until the saturation of answers was reached (i.e. after a certain number of interviews the answers tended to become repeated or equivalent; Lakatos and Marconi, 1991). In addition, we assessed three types of instrument validity: content, convergent and discriminant validity - all within the limitations of qualitative research.

\subsection{Data collection tool}

For the collection of primary data, a semi-structured script was developed, divided into four parts. Part 1 addressed company and respondent data. Part 2 included seven open-ended questions (Appendix 2) that served as a guide for the in-depth and audio-taped interview, so that details of the phenomenon could be retained for further analysis. In the open questions, the interviewees were able to express general attitudes and opinions about the questions presented. The open questions aimed to identify the main variables involving the research constructs exposed in the conceptual model, from the point of view of the SCM managers at the companies of the Campinas Technological Hub.

To obtain reliability of the qualitatively collected data, we sought to follow the qualitative research protocol elements recommended by Yin (2001), initial scheduling for field visits; choice of people and interview site; and previous training to help the interviewer 
discover motivations, beliefs, attitudes and sensations regarding the studied phenomenon. The data collected were treated by content analysis, according to Bardin's (1977) approach.

In general, the limitations of the qualitative research method are as follows:

- they are unstructured and exploratory, but although research carried out at this stage cannot be conducted in a formal way, it can provide valuable knowledge about the phenomenon studied;

- the analyses are based on in-depth examinations of personal, family and cultural human experience; and

- they are based on small samples, which indicates the in-depth interview as an appropriate strategy.

Part 3 referred to the closed questions (Appendix 1), and aimed to identify the degree of agreement or disagreement with the assertion presented in their respective constructs. The scale adopted was that of classification by items, considered non-comparative. The respondents did not compare the assertion being classified, either with another or against a specified standard. The respondents evaluated only one statement at a time, in the respective construct, indicating their degree of agreement or disagreement, according to six categories of responses that ranged from totally disagree $(\mathrm{DT}=1)$ to totally agree $(\mathrm{CT}=6)$.

The closed questions were distributed in three assertion blocks. The first one referred to the construct orientation of the SSCM, the second referred to the construct TIC and the third referred to the construct CA.

Figure 2 shows the constructs broken up into their measurements.

Before its definition, the script underwent successive pre-tests to determine the measures; eliminate possible problems of understanding in the questionnaire statement and the content of the assertions; and contribute to the formation of the research protocol.

Next, a sample of ten companies in the hub were selected by applying the accessibility criterion, using data available on the website of the innovation agency Inova, part of the

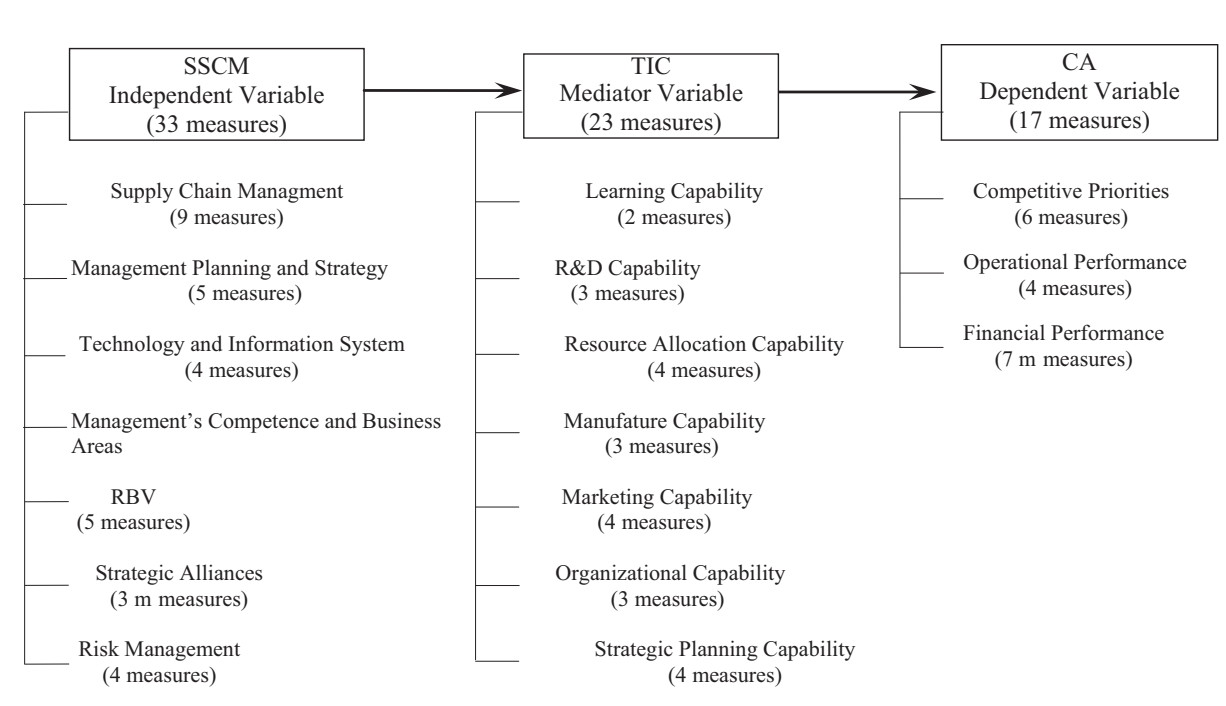

Role of
technological capabilities

253

Source: Authors

Figure 2.

The empirical model with its constructs and sub-constructs 
INMR

15,3

Campinas technological hub. First contacts were made with the supply chain managers to schedule a date, time and place for in-depth interviews.

Questionnaires with the closed-ended questions were used to collect data, which was then treated by the non-parametric Mann-Whitney U test. In this test, all calculations are done through ranks, not with actual values. It is commonly applied in ordinal data to compare two unpaired groups, to verify whether they belong to the same population. The Utest can be considered the non-parametric version of the $t$-test for independent samples.

Because the study deals with non-parametric distribution, three important criteria for the validation of the collected data were considered: the unidirectionality of the asymmetric relation, unidimensionality and multiple (or summed) scale. The relationship between a stimulus and a response is always unidirectional. The asymmetric relationship is the core of sociological analysis, in which it is postulated that one variable (called independent) produces a change in another (considered the dependent variable). When the direction of the asymmetrical relationship is not so obvious, Lakatos and Marconi (1991) suggest appealing to the temporal order, or the characteristics of fixity or changes of variables.

The unidimensionality, similar to the reliability of the construct, refers to the characteristic of a set of measures that has only one inherent trait or concept in common (Hair et al., 2005). The Cronbach Alpha coefficient is commonly used to measure the consistency of the unidimensionality or reliability of the construct.

The limitations of the quantitative method were: (a) the size and variability of the sample as these elements are important in the analysis of the data to obtain an acceptable level of statistical significance, usually 0.01 or 0.05 . For small $(n<30)$, or very small samples $(n<$ 12), Levine et al. (2005) suggest using the $t$-distribution. However, for ordinal data, which rarely has a normal distribution, the non-parametric Mann-Whitney $\mathrm{U}$ test was used in the data treatment to circumvent the problem of sample size.

\section{Data analysis and results}

To collect the data, ten interviews were conducted in ten organizations between April 27 and May 25, 2016.

\subsection{Demographic profile of respondents and companies}

The demographic profile of respondents and companies is shown in Table I.

In summary, the sample consisted of seven male and three female respondents. Six of the interviewees held positions of coordinators, three were managers and one was an auditor.

Regarding the level of education, nine respondents had postgraduate degrees (professional specialization or MBA) and one had an undergraduate degree. The training was predominantly in administration (six interviewees), but also in engineering, law, IT and economics.

Regarding time with the company, six respondents had been with the company for more than five years and four between two and five years. Six interviewees had been in their current position between two and five years, and four had been more than five years.

The companies surveyed operate in the sectors of food, automobiles, information technology, fiberglass, metallurgy and energy. In the analysis of the size of the companies, it was identified that 2 have up to 99 employees, 3 have between 100 and 499 employees and 5 have more than 500 employees. In terms of annual revenues in 2015, five companies earned less than R $\$ 90$ million, two earned between $\mathrm{R} \$ 90$ and $\mathrm{R} \$ 300$ million and three companies earned more than $\mathrm{R} \$ 300$ million. 


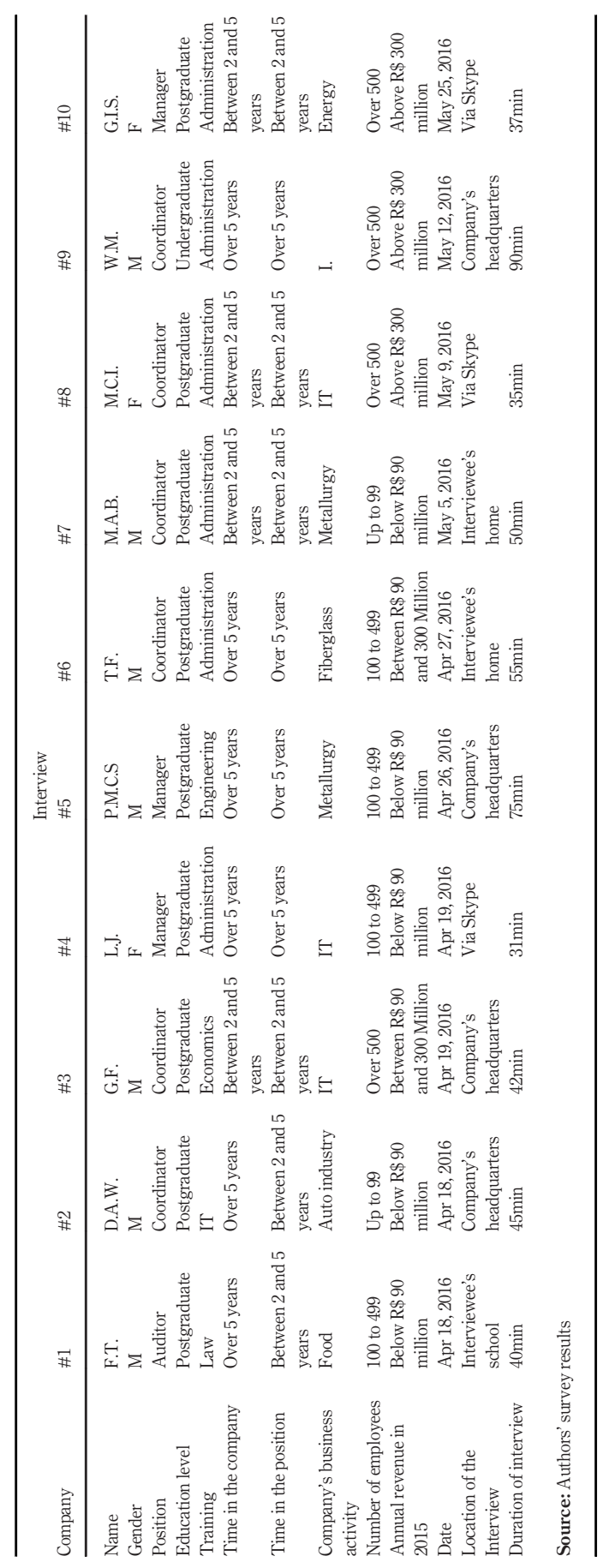

Role of technological capabilities

255

Table I. Demographic profile of respondents and sample companies 
INMR

15,3

\subsection{Analysis of qualitative data}

This section presents the analysis of respondents' spontaneous responses to the questions about the three constructs of the research model: SSCM, TIC and CA:

(1) Evidence of relationship: strategic management of the supply chain positively influences competitive advantage.

With regard to what makes up an effective SSCM, the following comments stand out:

Considering "effective" and "strategic", it can be synthesized as the coordination of activities related to the supply chain, which can deliver quality and agility, guaranteeing customer satisfaction and maximizing profits. It is understood that effective processes are important; involvement of different business areas; and information sharing. (Interviewee 2)

Finding the balance between quality, cost, delivery time, flexibility and innovation to meet the needs of the company and the customers. (Interviewee 4)

It is important to understand the dynamics of the market, the customers' needs and the supply chain structure of the company. (Interviewee 5)

The main strategies used by companies for SCM are as follows:

Partnerships with companies, such as long-term contracts and visiting programs, with the objective of exchanging experiences and knowledge of the reality of each partner company in the supply chain. (Interviewee 3 )

[...] the sharing of information; the effective planning for demand with participation of different business areas (such as logistics, IT, marketing and procurement); and the search for constant optimization of processes, which includes reducing bureaucracy and increasing control. (Interviewee 1)

[...] the definition of key suppliers for raw materials and services that add value to the final product. (Interviewee 5)

(2) Evidence of the relationship: strategic management of the supply chain positively influences the capabilities of technological innovation.

The main motivating factors for a company to invest in TIC are competitive advantage; cost reduction; optimization of production and delivery times; investment in new technologies; legal and economic issues (local and global); product quality enhancement; need for survival; international competition; demands by customers for greater technological content; integration of information systems; and improvements in sustainability.

Regarding the importance of constant technological innovation for the company, some comments of the interviewees were as follows:

Stay competitive in a globalized world. For the company, the issues related to technological innovation are directly linked to its survival. (Interviewee 7)

Technological innovation is a critical factor for the company's success because if the use of certain raw materials tends to grow in the industry, the level of quality required of the products by customers grows even more strongly, with zero tolerance for all types of error. This requires a thorough knowledge of the production process and absolute control of process parameters, which is provided through technology, especially information technology. (Interviewee 6) 
(3) Evidence of the relationship: technological innovation capabilities positively influence competitive advantage.

The ten interviewees identified several factors that make their companies competitive in the market: quality of final products; production and logistics costs; R\&D; innovation; SCM; better performance and agility in deliveries; low competition; customer relationships; delivery deadlines; research and service solutions; control of internal and external processes; and pioneering the development of equipment and processes in their sector.

The main indicators of financial performance are: net profit; EBITDA; liquidity index; ROI; partnership with suppliers (number of contracts); profitability; rentability; fixed and variable costs; gross revenue; and product contribution margin.

Regarding operational performance, the main indicators can be divided into production indicators (productivity indexes, lead time, equipment idleness, waste index, energy consumption and indirect manufacturing costs); purchases (number of items purchased per buyer, number of items on contract, standardization and/or replacement of materials and inventory turnover); and customer relations (customer satisfaction, delivery time, technical assistance and rework).

The results obtained with the qualitative data also demonstrate that TIC has a mediating effect between SSCM and CV: the respondents emphasized its importance and mediation in their organizational practices. For the companies surveyed, the questions about technological innovation are directly related to obtaining a competitive advantage, which can include producing something new, or improving or evolving what is already in use.

\subsection{Analysis of quantitative data}

To measure the internal consistency or the reliability of the unidimensionality, the Cronbach's Alpha coefficient was used. The value for the SSCM construct was 0.985 for the TIC 0.983 and for the CA 0.964 . All these values are above the recommended minimum of 0.7 , thereby denoting that the measures can be summed in such a way as to represent the construct as a whole.

Table II shows the result of the ordering of the ranks of the SSCM, TIC and CA constructs in ascending order of the CA construct.

When the CA is shown in ascending order, the relations of CA with TIC and SSCM are asymmetrical. Companies with lower CA ranks do not correspond to the lowest rank of SSCM (with a score of 101). Likewise, Rank 3 of the CA (score equal to 69) does not

\begin{tabular}{lccrr}
\hline Original sample & Sorted sample & SSCM & TIC & CA \\
\hline 4 & 1 & 112 & 55 & 31 \\
1 & 2 & 105 & 73 & 51 \\
9 & 3 & 164 & 122 & 69 \\
3 & 4 & 148 & 93 & 73 \\
5 & 5 & 155 & 108 & 74 \\
8 & 6 & 187 & 120 & 82 \\
2 & 7 & 101 & 68 & 87 \\
6 & 8 & 188 & 125 & 89 \\
7 & 9 & 192 & 123 & 90 \\
10 & 10 & 195 & 137 & 101
\end{tabular}

Source: Authors' research data

Table II.

Added scale and CA ranks 
INMR

15,3

258

correspond to Rank 3 of TIC (which is equal to 73). In applying the Mann-Whitney U test, it is verified that the three constructs are statistically significant $(\alpha \leq 0.05)$, as presented in Table III, thus confirming the independence of the samples.

Finally, the results of the verification of TIC mediation in the relationship between SSCM and CA are shown. By using the mediation rule suggested by Baron and Kenny (1986) and Lakatos and Marconi (1991), we have:

- the original direct relationship between CA by SSCM - path c [Figure 1(a)].

The results are shown in Table IV and Figure 3.

In the original direct relationship between CA by SSCM, as the SSCM level decreases, so does the competitive advantage (CA), which shows the direct impact of SSCM on CA:

- The relationship between TIC by SSCM - Path a [Figure 1(b)].

The results are shown in Table $\mathrm{V}$ and Figure 4.

In the direct relation of TIC by SSCM, there is also a direct influence by the degree of SSCM on TIC. That is, as SSCM decreases, so does the importance of TIC, which demonstrates that variations (high or low) in TIC also occur (high or low) in SSCM:

- The relationship between CA by TIC - Path b [Figure 1(b)].

Table III.

Mann-Whitney U test for the SSCM, TIC and CA constructs

\begin{tabular}{lccr}
\hline & SSCM-TIC & SSC-CA & TIC-CA \\
\hline Significance (two-tailed) & 0.013 & 0.000 & 0.045 \\
Source: Authors' research data & & & \\
\hline
\end{tabular}

Table IV.

\begin{tabular}{lrrrrr}
\hline & & SSCM-High & & & SSCM-Low \\
CA & $N$ & $(\%)$ & 18 & $(\%)$ \\
\hline CA-High & 147 & 55 & 47 & 28 \\
CA-Low & 118 & 45 & 65 & 100 \\
TOTAL & 265 & 100 & & \\
Source: Authors' research data & & &
\end{tabular}

Figure 3.

Graph CA $\times$ SSCM

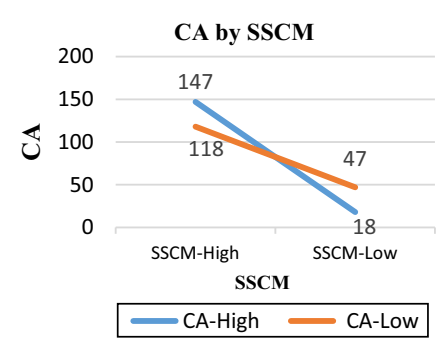

(score)

Source: Authors' research data 
The results are shown in Table VI and Figure 5.

For the direct relation of TIC by CA, the impact of the TIC construct on CA is observed. As in the previous relation, as TIC decreases, so does the competitive advantage (CA), thereby denoting the direct relation between the constructs:

- The relationship of TIC mediation in the relationship between SSCM and CA - Path $c^{\prime}$ [Figure 1(b)].

The results are shown in Table VII and Figure 6.

One can verify the mediation of TIC in the relationship between SSCM and CA (mediation effect) by comparing the magnitudes of the regression coefficients, $c$ and c'. In the regression coefficient $\mathrm{c}$, after the TIC control, represented by the paths a and b (shown in Table VII and Figures 6 and 7), it is observed that there was attenuation or fading of path c (shown in Table IV and Figure 3), showing that TIC had a mediating role in the relationship between SSCM and CA.

In terms of the assumptions, which do not imply statistical testing, it can be inferred that all of them support the anticipated answers to the formulated problem - that is, TIC plays a

\begin{tabular}{lrrrrr}
\hline & & SSCM-High & & & \\
TIC & $N$ & $(\%)$ & SSCM-Low & $(\%)$ & \\
\hline TIC-High & 161 & 61 & 4 & 6 & Table V. \\
TIC-Low & 104 & 39 & 61 & 94 & TIC by SSCM \\
TOTAL & 265 & 100 & 65 & 100 & \\
\hline
\end{tabular}

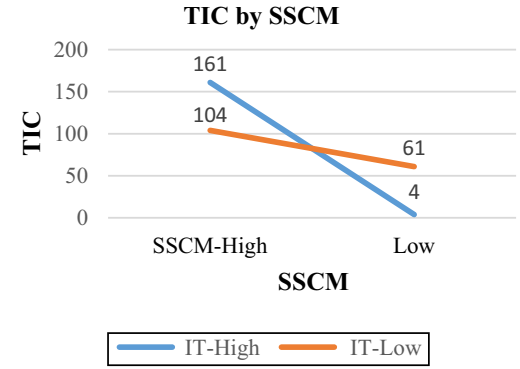

Source: Authors' research data
Figure 4. Graph TIC $\times$ SSCM (score)

\begin{tabular}{lrrrrr}
\hline & & TIC-High & & & TIC-Low \\
CA & $N$ & $(\%)$ & 15 & $(\%)$ \\
\hline CA-High & 100 & 58 & 44 & 25 \\
CA-Low & 71 & 42 & 59 & 75 \\
TOTAL & 171 & 100 & & 100
\end{tabular}

Source: Authors' research data

Table VI. CA by TIC 
INMR

15,3

260

Figure 5.

$\mathrm{CA} \times$ TIC (Score)

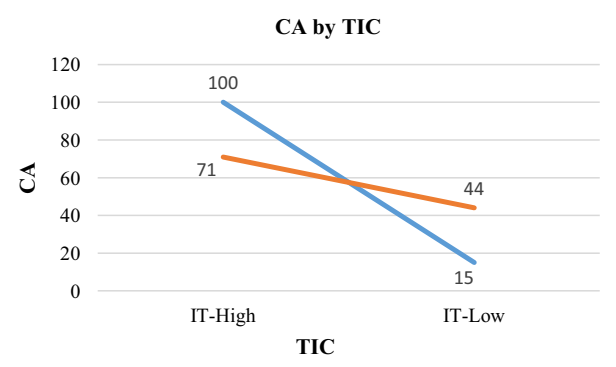

$\longrightarrow$ CA-High $=$ CA-Low

Source: Authors' research data

\section{CA by TIC an}

SSCM

\begin{tabular}{lrrrrrrrr}
\hline & \multicolumn{3}{c}{ TIC-High } & \multicolumn{3}{c}{ TIC-Low } \\
\multicolumn{2}{c}{ SSCM-Alta } & \multicolumn{2}{c}{ SSCM-Low } & \multicolumn{2}{c}{ SSCM-High } & \multicolumn{2}{c}{ SSCM-Low } \\
CA & $N$ & $(\%)$ & $N$ & $(\%)$ & \multicolumn{1}{c}{$N$} & $(\%)$ & $N$ & $(\%)$ \\
\hline CA-High & 95 & 58 & 2 & 58 & 26 & 25 & 15 & 25 \\
CA- Low & 66 & 42 & 2 & 42 & 78 & 75 & 46 & 75 \\
TOTAL & 161 & 100 & 4 & 100 & 104 & 100 & 61 & 100 \\
\multicolumn{2}{l}{ Source: Authors' research data } & & & & & & \\
\end{tabular}

Figure 6.

CA by TIC and SSCM (TIC-High) (score)

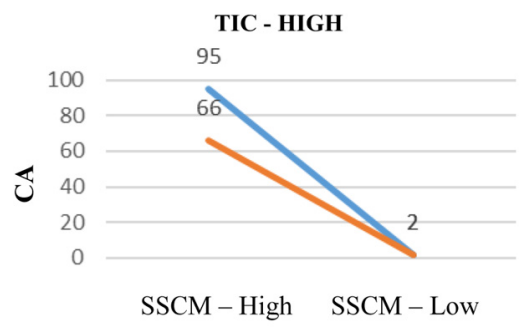

$$
\begin{array}{|c|}
\text { SSCM } \\
\hline \text { CA-High } \rightleftharpoons \text { CA-Low }
\end{array}
$$

Source: Authors' research data

mediating role in the relationship between SSCM and CA. Briefly, the assumptions defined for solving the problem are shown in Table VIII.

In summary, it can first be stated that TIC is a mediating variable in the relationship between the independent variable (SSCM) and the dependent variable $(\mathrm{CA})$ because the three asymmetric relations are found as follows:

(1) between the independent variable (SSCM) and the dependent variable (Ca);

(2) between the independent variable (SSCM) and the mediator variable (TIC) - in this case, the mediator variable acts as dependent on the independent variable (SSCM); and 
TIC - LOW

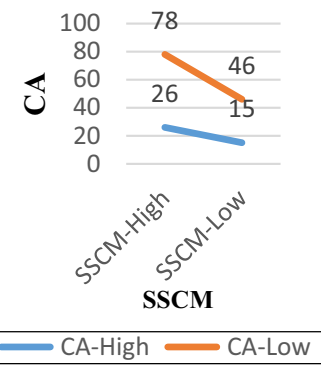

Source: Authors' research data

\section{Role of technological capabilities}

261

Figure 7.

CA by TIC and SSCM (TIC-Low) (score)

\begin{tabular}{lll}
\hline & Assumptions & \\
\hline SSCM $\rightarrow$ CA & $\mathrm{S}_{1}$ & Decision \\
SSCM $\rightarrow$ TIC & $\mathrm{S}_{2}$ & Supports \\
TIC $\rightarrow$ CA & $\mathrm{S}_{3}$ & Supports \\
Mediation & $\mathrm{S}_{4}$ & Supports \\
& & Supports
\end{tabular}

Source: Authors' research data

Table VIII.

Assumptions for solving the research problem

(3) both the SSCM and TIC variables act as independent of the dependent variable (CA).

Second, the relationship between the independent variable (SSCM) and the dependent variable (CA) is owing to the mediator variable (TIC) because when exercising control over the test factor, represented by the mediator variable (TIC), as shown in Table VII, the original relationship between the independent variable (SSCM) and the dependent variable (CA) was attenuated: that is, it became weaker.

The empirical evidence in the qualitative and quantitative analyses contributed to the academic literature and management practices and achieved the objectives proposed in this study. The nature of the technology industry requires gaining competitive advantage, which depends on the ability of each organization to balance SSCM and the use of technological capabilities. Companies' TIC represents a challenge for managers and organizations in terms of adding value and impact to $\mathrm{CA}$.

\section{Final considerations}

Given the results obtained, this study leads to a number of implications for academic development and managerial practices.

The first is the need for a more macro-oriented approach to TICs, more specifically in technology hubs, from the point of view of the strategic management of the supply chain. The theme should also be adapted to the Brazilian context, as it is still under-studied in domestic industries. 
INMR

15,3

The main benefits obtained by enterprises in terms of technological innovation include innovation promotion strategies, organizational management, culture and knowledge management, R\&D program management and the management of benefits and fiscal incentives for innovation. With regard to strategic management, the following actions can be listed: strategic consulting and business and project advisory services; modeling and preparation of business plans; strategic planning and action plans; creation of business improvement and excellence programs; and promotion of capacity-building and customized training.

The present study set out to fill a knowledge gap, in methodological terms, in the effort to understand the relationship between strategic supply chain management, technological innovation capabilities and competitive advantage, thereby contributing in a relevant way to existing studies on technology hubs. Finally, because this study is exploratory, the estimated model can be considered a best estimate.

The size of the sample and the data collection for convenience are limitations to this study, so the results obtained should be received with caveats. A further limitation is that the data was only collected once, using a cross-sectional design.

To pursue this avenue of study, we suggest the following:

- to expand the sample for better consistency of the data obtained, prioritizing the survey research method, so that the results can be generalized;

- perform the exploratory factorial analysis by research construct and compare it with the results obtained in the present study; and

- build the relationship between the research constructs through the analysis of structural equations and linear regression, to study more deeply the mediating influence of TIC within the proposed model.

\section{References}

Amit, R. and Schoemaker, P. (1993), "Strategic assets and organizational rent", Strategic Management Journal, Vol. 14 No. 1, pp. 33-46, doi: 10.1002/smj.4250140105.

Aquim, T. (2015). "Campinas: a força do setor de data center do Brasil", available at: www. datacenterdynamics.com.br/focus/archive/2015/06/campinas-for $\%$ C3\%A7a-do-setor-de-datacenter-do-brasil

Azubuike, V.M.U. (2013), “Technological innovation capability and firm's performance in new product development", Communications of the IIMA, Vol. 13 No. 1, pp. 43-55, available at: http:// scholarworks.lib.csusb.edu/ciima/vol13/iss1/4/

Bardin, L. (1977), Análise De Conteúdo, Edições, Lisboa, p. 70.

Barney, J.B. (1991), "Firm resources and sustained competitive advantage", Journal of Management, Vol. 17 No. 1, pp. 99-120, doi: 10.1177/014920639101700108.

Baron, R.M. and Kenny, D.A. (1986), "The moderator-mediator variable distinction in social psychological research: conceptual, strategic, and statistical considerations", Journal of Personality and Social Psychology, Vol. 51 No. 6, pp. 1173-1182, doi: 10.1037/0022-3514.51.6.1173.

Bell, M. and Pavitt, K. (1993), "Technological accumulation and industrial growth: contrasts between developed and developing countries", Industrial and Corporate Change, Vol. 2 No. 2, pp. 157-211, doi: $10.1093 / \mathrm{icc} / 2.2 .157$.

Bell, M. and Pavitt, K. (1995), "The development of technological capabilities", in Irfan ul, H. (Ed.), Trade, Technology and International Competitiveness, The World Bank, Washington, DC, pp. 69-101. 
Burgelman, R., Maidique, M.A. and Wheelweight, S.C. (2004), Strategic Management of Technology and Innovation, McGraw Hill, New York, NY.

Chiesa, V., Coughlan, P. and Voss, C.A. (1996), "Development of a technical innovation audit”, Journal of Product Innovation Management, Vol. 13 No. 2, pp. 105-136, doi: 10.1111/1540-5885.1320105.

Christensen, J.F. (1995), “Asset profiles for technological innovation”, Research Policy, Vol. 24 No. 5, pp. 727-745, doi: 10.1016/0048-7333(94)00794-8.

Christopher, M. (2000), "The agile supply chain: competing in volatile markets", Industrial Marketing Management, Vol. 29 No. 1, pp. 37-44, doi: 10.1016/S0019-8501(99)00110-8.

Cooper, M.C., Lambert, D.M. and Pagh, J.D. (1997), "Supply chain management: more than a new name for logistics", The International Journal of Logistics Management, Vol. 8 No. 1, pp. 1-13, doi: 10.1108/09574099710805556.

Creswell, J.W. (2007), Projeto De Pesquisa: métodos Qualitativo, Quantitativo e Misto, ARTMED, Porto Alegre, RS.

D'Aveni, R.A. and Gunther, R. (1994), Hypercompetition: managing the Dynamics of Strategic Maneuvering, Free Press, New York, NY.

Dierickx, I. and Cool, K. (1989), "Asset stock accumulation and sustainability of competitive advantage”, Management Science, Vol. 35 No. 12, pp. 1504-1513, doi: 10.1287/mnsc.35.12.1504.

Eltantawy, R.A., Giunipero, L. and Fox, G.L. (2009), "A strategic skill based model of supplier integration and its effect on supply management performance", Industrial Marketing Management, Vol. 38 No. 8, pp. 925-936, doi: 10.1016/j.indmarman.2008.12.022.

Ferdows, K. and De Meyer, A. (1990), "Lasting improvements in manufacturing performance: in search of a new theory", Journal of Operations Management, Vol. 9 No. 2, pp. 168-184, doi: 10.1016/02726963(90)90094-T.

Ghenawat, P. (1991), Commitment: The Dynamic of Strategy, Free Press, New York, NY.

Guan, J. and Ma, N. (2003), "Innovative capability and export performance of Chinese firms", Technovation, Vol. 23 No. 9, pp. 737-747, doi: 10.1016/S0166-4972(02)00013-5.

Gunasekaran, A., Patel, C. and McGaughey, R.E. (2004), "A framework for supply chain performance measurement”, International Journal of Production Economics, Vol. 87 No. 3, pp. 333-347, doi: 10.1016/j.jppe.2003.08.003.

Hair, J.F., Jr, Babin, B., Money, A.H. and Samouel, P. (2005), Análise Multivariada De Dados, 5a ed., Bookman, Porto Alegre, RS.

Hall, R.H. (2004), Organizações: estruturas, Processos e Resultados, Pearson Prentice Hall, São Paulo.

Hu, M.C. (2012), "Technological innovation capabilities in the thin film transistor-liquid crystal display industries of Japan, Korea, and Taiwan", Research Policy, Vol. 41 No. 3, pp. 541-555, doi: 10.1016/ j.respol.2011.10.013.

Inova (2016). "Conheça o parque científico e tecnológico da unicamp", disponível em: www.inova. unicamp.br/sobre-a-inova/ (acessado 19 2016).

Jacobson, R. (1992), “The ‘Austrian' school of strategy”, Academy of Management Review, Vol. 17 No. 4, pp. 782-807, doi: 10.5465/AMR.1992.4279070.

Kaplan, R.S. and Norton, D.P. (1992), "The balanced scorecard: measures that drive performance", Harvard Business Review, Vol. 70 No. 1, pp. 71-79, available at: https:/umei007-fall10. wikispaces.com/file/view/Kaplan\%26Nortonbalanced+scorecard.pdf

Lakatos, E.M. and Marconi, M. d A. (1991), Metodologia Científica, 2a ed., Atlas, São Paulo, SP.

Lall, S. (1992), "Technological capabilities and industrialization", World Development, Vol. 20 No. 2, pp. 165-168, doi: 10.1016/0305-750X(92)90097-F.

Lau, A.K.W., Yam, R.C.M. and Tang, E.P.Y. (2010), "The impact of technological innovation capabilities on innovation performance", Journal of Science and Technology Policy in China, Vol. 1 No. 2, pp. 163-186, doi: 10.1108/17585521011059893. 
INMR 15,3

Lawson, B., Krause, D. and Potter, A. (2015), "Improving supplier new product development performance: the role of supplier development", Journal of Product Innovation Management, Vol. 32 No. 5, doi: 10.1111/jpim.12231.

Lee, V.H., Ooi, K.B., Chong, A.Y.L. and Seow, C. (2014), "Creating technological innovation via green supply chain management: an empirical analysis", Expert Systems with Applications, Vol. 41 No. 16, pp. 6983-6994, doi: 10.1016/j.eswa.2014.05.022.

Levine, D.M., Berenson, M.L. and Stephan, D. (2005), Estatística: Teoria e Aplicações Usando o Microsoft Excel Em Português, 3a ed., LTC, Rio de Janeiro, RJ.

Li, S., Ragu-Nathanb, B., Ragu-Nathanb, T.S. and Rao, S.S. (2006), "The impact of supply chain management practices on competitive advantage and organization performance", Omega-International Journal of Management Science, Vol. 34 No. 2, pp. 107-124, doi: 10.1016/j.omega.2004.08.002.

Li, W., Humphreys, P.K., Yeung, A.C.L. and Cheng, T.C.E. (2012), "The impact of supplier development on buyer competitive advantage: a path analytic model", International Journal of Production Economics, Vol. 135 No. 1, pp. 353-366, doi: 10.1016/j.ijpe.2011.06.019.

Lin, H.F. (2014), "The impact of socialization mechanisms and technological innovation capabilities on partnership quality and supply chain integration", Information Systems and e-Business Management, Vol. 12 No. 2, pp. 285-306, doi: 10.1007/s10257-013-0226-z.

Melnyk, S.A., Lummus, R., Vokurka, R.J. and Sandor, J. (2006), Supply Chain Management 2010 and beyond Mapping the Future of the Strategic Supply Chain, Michigan State University, Michigan, MI.

Noor, N.A.M. and Aljababi, A.Q.R.A. (2016), "Moderating role of absorptive capacity between entrepreneurial orientation and technological innovation capabilities", International Review of Management and Marketing, Vol. 6 No. 4, pp. 704-710, doi: 10.1108/IJEBR-07-2017-0233.

Ortega, M.J.R. (2010), "Competitive strategies and firm performance: technological capabilities moderating roles", Journal of Business Research, Vol. 63 No. 12, pp. 1273-1281, doi: 10.1016/j. jbusres.2009.09.007.

Paulraj, A. and Chen, I.J. (2007), "Strategic buyer-supplier relationships, information technology and external logistics integration", The Journal of Supply Chain Management, Vol. 43 No. 2, pp. 1-14, doi: 10.1111/j.1745-493X.2007.00027.x.

Poirier, C.C. and Reiter, S.E. (1996), Supply Chain Optimization, Building the Strongest Total Business Network, Berrett-Koehler, San Francisco, CA.

Porter, M.E. (1980), Competitive Strategy, Free Press, New York, NY.

Ritzman, L.P. and Krajewski, L.J. (2004), Administração Da Produção e Operações, Pearson Prentice Hall, São Paulo, SP.

Sanchez, R., Heene, A. and Thomas, H. (1996), Dynamics of Competence-Based Competition: theory and Practice in the New Strategic Management, Elsevier, Amsterdam, pp. 1-35.

Shan, J. and Jolly, D.R. (2013), "Technological innovation capabilities, product strategy, and firm performance: the electronics industry in China", Canadian Journal of Administrative Sciences/ Revue Canadienne Des Sciences De L'administration, Vol. 30 No. 3, pp. 159-172, doi: 10.1002/ cjas.1256.

Shapiro, C. (1989), "The theory of business strategy", RAND Journal of Economics, Vol. 20 No. 1, pp. 125-137, doi: 10.2307/2555656.

Simchi-Levi, D., Kaminsky, P. and Simchi-Levi, E. (2008), Designing and Managing the Supply Chain: concepts, Strategies, and Case Studies, McGraw-Hill; Irwin, Boston, MA.

Sukati, I., Hamid, A.B., Baharun, R. and Yusoff, R.M. (2012), "The study of supply chain management strategy and practices on supply chain performance", Procedia - Social and Behavioral Sicences, Vol. 40, pp. 225-233, doi: 10.1016/j.sbspro.2012.03.185.

Tang, Y.C. and Liou, F.M. (2010), "Does firm performance reveal its own causes? The role of bayesian inference”, Strategic Management Journal, Vol. 31 No. 1, pp. 39-57, doi: 10.1002/smj.799. 
Teece, D.J., Pisano, G. and Shuen, A. (1997), "Dynamic capabilities and strategic management", Strategic Management Journal, Vol. 18 No. 7, pp. 509-533, doi: 10.1002/(SICI)1097-0266(199708) 18:7<509::AID-SMJ882>3.0.CO;2-Z.

Vasconcelos, F.C. and Cyrino, A.B. (2000), "Vantagem competitiva: os modelos teóricos atuais e a convergência entre estratégia e teoria organizacional", Revista De Administração De Empresas, Vol. 40 No. 4, pp. 20-37, doi: 10.1590/S0034-75902000000400003.

Vergara, S.C. (2013), Projetos e Relatórios De Pesquisa Em Administração, 14a ed., Atlas, São Paulo, SP, p. 94.

Wiggins, R.R. and Ruefli, T.W. (2002), "Sustained competitive advantage: temporal dynamics and the incidence and persistence of superior economic performance", Organization Science, Vol. 13 No. 1, pp. 81-105, doi: 10.1287/orsc.13.1.81.542.

Yam, C.M., Guan, J.C., Pun, K.F. and Tam, P.Y. (2004), "An audit of technological innovation capabilities in Chinese firms: some empirical findings in beijing, China", Research Policy, Vol. 33 No. 8, pp. 1123-1250, doi: 10.1016/j.respol.2004.05.004.

Yam, R.C.M., Lo, W., Tang, E.P.Y. and Lau, A.K.W. (2010), "Technological innovation capabilities and firm performance", International Scholarly and Scientific Research \& Innovation, Vol. 4 No. 6, pp. 1056-1064, doi: 10.1999/1307-6892/11412.

Yin, R.K. (2001), Estudo De Caso: planejamento e Métodos, 2a ed., Bookman, Porto Alegre, RS.

Youn, S., Yang, M.G., Hong, P. and Park, K. (2013), "Strategic supply chain partnership, environmental supply chain management practices, and performance outcomes: an empirical study of korean firms",Journal of Cleaner Production, Vol. 56, pp. 121-130, doi: 10.1016/j.jclepro.2011.09.026.

\section{Further reading}

Hill, T. (1994), Manufacturing Strategy: text and Cases, 2th ed., Richard D. Irwin Inc, New York, NY.

Peteraf, M.A. (1993), “The cornerstones of competitive advantage”, Strategic Management Journal, Vol. 14 No. 3, pp. 179-191, doi: 10.1002/smj.4250140303.

Skinner, W. (1969), "Manufacturing: missing link in corporate strategy", Harvard Business Review, Vol. 4 No. 3, pp. 136-145, doi: 10.1111/j.1937-5956.1996.tb00381.x. 
In this part of the questionnaire, divided into blocks, please note the degree of agreement with each statement presented. Consider level 1 as totally disagree and level 6 as totally agree.

Block 1: The strategies of the supply chain management are based on:

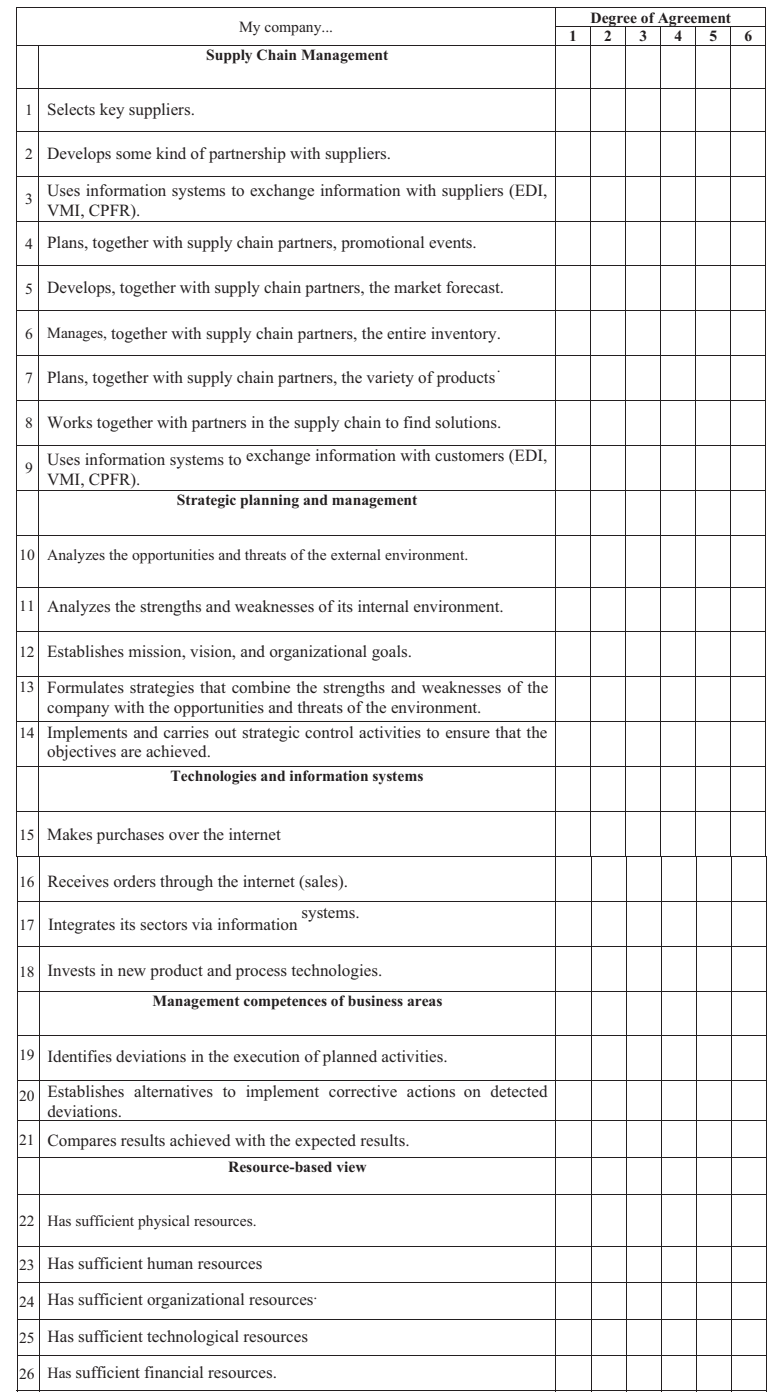

(continued) 


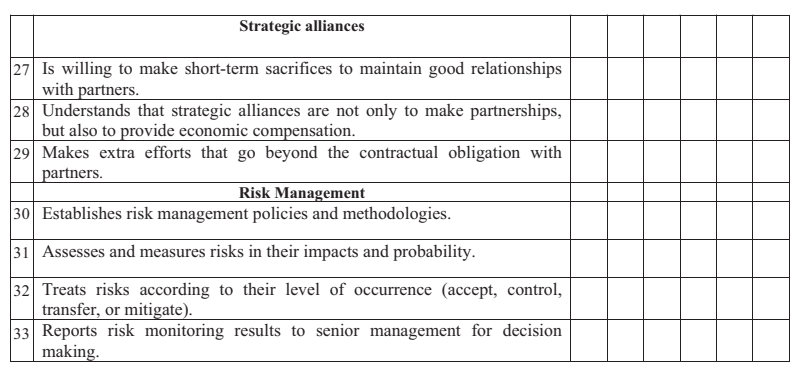

\section{Role of technological capabilities}

Block 2: Technological innovation capabilities are perceived when:

\begin{tabular}{|c|c|c|c|c|c|c|c|}
\hline & & & & ree & Agr & met & \\
\hline & My company ........ & 1 & 2 & 3 & 4 & 5 & 6 \\
\hline & Learning capability & & & & & & \\
\hline 1 & \begin{tabular}{|l}
$\begin{array}{l}\text { Encourages work teams to identify opportunities for } \\
\text { improvement. }\end{array}$ \\
\end{tabular} & & & & & & \\
\hline 2 & Adopts the evaluation of knowledge in its daily activities. & & & & & & \\
\hline & R\&D capability & & & & & & \\
\hline 3 & $\begin{array}{l}\text { Has high quality and fast feedback in design and engineering } \\
\text { production. }\end{array}$ & & & & & & \\
\hline 4 & $\begin{array}{l}\text { Has good mechanisms for transferring technologies from } \\
\text { research to product development. }\end{array}$ & & & & & & \\
\hline 5 & $\begin{array}{l}\text { Has a strong market share in the process of technological } \\
\text { innovation. }\end{array}$ & & & & & & \\
\hline & Resources allocation capability & & & & & & \\
\hline 6 & Attaches great importance to human resources. & & & & & & \\
\hline 7 & Has ongoing human resources programs. & & & & & & \\
\hline 8 & $\begin{array}{l}\text { Selects the key person in each functional department for the } \\
\text { innovation process. }\end{array}$ & & & & & & \\
\hline 9 & Provides constant capital supplement in innovation activities. & & & & & & \\
\hline & Manufacturing capability & & & & & & \\
\hline 10 & $\begin{array}{l}\text { Has a production department with the capacity to transform } \\
\text { research and development into effective production. }\end{array}$ & & & & & & \\
\hline 11 & Effectively applies advanced production methods. & & & & & & \\
\hline 12 & Has trained production staff. & & & & & & \\
\hline & Marketing capability & & & & & & \\
\hline 13 & Conducts relationship management with key clients. & & & & & & \\
\hline 14 & Has good knowledge of the different market segments. & & & & & & \\
\hline 15 & Has a highly efficient sales force. & & & & & & \\
\hline 16 & Offers excellent after-sales service. & & & & & & \\
\hline & Organization capability & & & & & & \\
\hline 17 & Can reconcile several innovation projects in parallel. & & & & & & \\
\hline 18 & $\begin{array}{ll}\text { Has good coordination and cooperation between the } \\
\text { departments of research and development, marketing and } \\
\text { production. }\end{array}$ & & & & & & \\
\hline 19 & $\begin{array}{l}\text { Places integration and control of the main functions of the } \\
\text { company with top management. }\end{array}$ & & & & & & \\
\hline & Strategic planning capability & & & & & & \\
\hline 20 & Has high capacity to identify internal strengths and weaknesses. & & & & & & \\
\hline 21 & Has high capacity to identify external opportunities and threats. & & & & & & \\
\hline 22 & Has clear and objective goals. & & & & & & \\
\hline 23 & $\begin{array}{l}\text { Has a strong market share in the process of technological } \\
\text { innovation. }\end{array}$ & & & & & & \\
\hline
\end{tabular}


INMR

15,3

268
Block 3: My company has a competitive advantage over competitors when it:

\begin{tabular}{|c|c|c|c|c|c|c|c|}
\hline \multirow{2}{*}{\multicolumn{2}{|c|}{ My company ... }} & \multirow[b]{2}{*}{1} & \multicolumn{5}{|c|}{ Degree of Agreement } \\
\hline & & & \multirow{2}{*}{\multicolumn{2}{|c|}{$2 \quad 3$}} & \multirow[t]{2}{*}{4} & & \multirow[t]{2}{*}{6} \\
\hline & Competitive priorities & & & & & & \\
\hline 1 & Can offer lower prices than its competitors. & & & & & & \\
\hline 2 & $\begin{array}{l}\text { Can offer products compliant with the technical specifications of } \\
\text { the project. }\end{array}$ & & & & & & \\
\hline 3 & Produces products with a high quality of design and finish. & & & & & & \\
\hline 4 & Is the first to introduce new products to the market. & & & & & & \\
\hline 5 & $\begin{array}{l}\text { Has the ability to change the design of the product to customize } \\
\text { it according to the customer's need. }\end{array}$ & & & & & & \\
\hline \multirow[t]{2}{*}{6} & Meets delivery deadlines. & & & & & & \\
\hline & Operational performance & & & & & & \\
\hline 7 & Has high employee productivity. & & & & & & \\
\hline 8 & Has low rates of rework and scrap. & & & & & & \\
\hline 9 & Offers good technical assistance. & & & & & & \\
\hline \multirow[t]{2}{*}{10} & Attempts to reduce lead time and setup time. & & & & & & \\
\hline & Financial performance & & & & & & \\
\hline 11 & Has a good profit margin on sales. & & & & & & \\
\hline 12 & Has increased sales in the international market. & & & & & & \\
\hline 13 & Has increased sales in the domestic market. & & & & & & \\
\hline 14 & Has a larger market share. & & & & & & \\
\hline 15 & Has higher billing. & & & & & & \\
\hline 16 & Has higher return on investment (ROI). & & & & & & \\
\hline 17 & \begin{tabular}{|l} 
Has greater gross profitability. \\
\end{tabular} & & & & & & \\
\hline
\end{tabular}

\section{Appendix 2. Semi-structured - Qualitative Roadmap}

- What constitutes effective strategic supply chain management?

- What are the main strategies used by your company for supply chain management?

- What are the main motivating factors for your company to invest in technological innovation capabilities?

- How important is constant technological innovation for your company?

- What are the key factors that make your company competitive in the market?

- When you think about your company's financial performance, and which indicators do you consider most important?

- When you think about your company's operational performance, and which indicators do you consider important?

\section{Corresponding author}

Valdir Antonio Vitorino Filho can be contacted at: valdir.vitorino@gmail.com

For instructions on how to order reprints of this article, please visit our website: 